\title{
Coeficientes de digestibilidade aparente de alimentos energéticos para juvenis de surubim
}

\author{
Edgar de Alencar Teixeira ${ }^{1}$, Eloísa de Oliveira Simões Saliba ${ }^{1}$, Ana Carolina Castro Euler ${ }^{1}$, \\ Paulo Mário Carvalho de Faria ${ }^{1}$, Daniel Vieira Crepaldi ${ }^{1}$, Lincoln Pimentel Ribeiro ${ }^{1}$ \\ ${ }^{1}$ Laboratório de Aquacultura, Departamento de Zootecnia da Escola de Veterinária da Universidade Federal de Minas Gerais. Av. Antônio \\ Carlos, 6627. Belo Horizonte, MG.
}

RESUMO - Neste trabalho, determinou-se o valor nutritivo de quatro alimentos energéticos (fubá de milho, sorgo, farelo de arroz integral e quirera de arroz) para juvenis de surubim. Os coeficientes de digestibilidade aparente da matéria seca (MS), proteína bruta (PB) e energia bruta (EB) foram avaliados pela metodologia de substituição do alimento numa ração-referência usando-se $0,1 \%$ de óxido crômico como indicador externo. Utilizaram-se 240 alevinos com $30 \mathrm{~g}$ de peso médio distribuídos em tanques apropriados para coleta de fezes. O delineamento foi inteiramente casualizado com quatro dietas, cada uma com quatro repetições. O coeficiente de digestibilidade aparente da matéria seca do fubá de milho foi de 62,3\%; do farelo de arroz, 59,7\%; da quirera de arroz, 40,4\%; e do sorgo, 38\%. Os coeficientes de digestibilidade da proteína bruta, nesta ordem, foram 87,$4 ; 83,8 ; 85,3$; e $81,1 \%$; e os da energia bruta, 62,$4 ; 66,4 ; 46,9$ e $47,8 \%$. Entre os alimentos avaliados, o que possui maior digestibilidade da matéria seca, proteína bruta e energia bruta é o farelo de arroz e o de menor digestibilidade, o sorgo.

Palavras-chave: avaliação de alimentos, espécies carnívoras, pintado, Pseudoplatystoma

\section{Apparent digestibility coefficients of different energetic ingredients for surubim juveniles}

\begin{abstract}
It was determined, in this work, the nutritional value of four energetic feeds (corn meal, sorghum, whole rice bran, and ground rice) for surubim juveniles. Apparent digestibility coefficients of dry matter (DM), crude protein (CP), and gross energy (GE) were evaluated by food replacement methodology in a reference-feeding using $0.1 \%$ of chromic oxide as an external marker. It was used 240 fingerlings with an average weight of $30 \mathrm{~g}$ distributed in tanks fitted for faeces collection. A complete random design with four diets, each one with four replicates, was used. Apparent digestibility coefficient of dry matter for corn meal was $62.3 \%$; for rice bran, $59.7 \%$; for ground rice, $40.4 \%$, and for sorghum, $38 \%$. Digestibility coefficients for crude protein were, in this order, the following: 87.4, 83.8, 85.3 and $81.1 \%$ and digestibility coefficient for gross energy were: $62.4,66.4,46.9$ and $47.8 \%$. Among the evaluated feeds, the one with the highest digestibility of dry matter, crude protein, and gross energy is the rice bran and the one with the lowest digestibility is the sorghum.
\end{abstract}

Key Words: Brazilian catfish, carnivorous species, feed evaluation, Pseudoplatystoma

\section{Introdução}

No Brasil, apesar da crescente demanda por rações comerciais para o surubim (Pseudoplatystoma sp), existem poucos trabalhos que tratam da avaliação de alimentos para essa espécie. A falta de dados concretos sobre a avaliação de alimentos e exigências nutricionais faz com que as deficiências na alimentação e nutrição desses peixes sejam responsáveis por altos índices de mortalidade, baixa eficiência alimentar e baixo desempenho (Teixeira, 2008).

A ração é muito importante, pois, quando formulada adequadamente, permite maior eficiência no uso de seus nutrientes tornando a composição química do corpo e da carne de peixes mais apropriada para conservação e o consumo humano (Burkert et al, 2008). A formulação de dietas para peixes conta com informações genéricas contidas no NRC (1993). Contudo, inúmeras espécies de interesse zootécnico, como o surubim, ainda não possuem informações precisa sobre suas necessidades nutricionais e a digestibilidade de alimentos.

A determinação da digestibilidade de alimentos utilizados na elaboração de dietas para peixes é de fundamentalpara melhoria de sua eficiência alimentar. Além disso, estes estudos permitem conhecer os alimentos que proporcionam baixos excedentes de nutrientes ao meio, 
principalmente nitrogênio e fósforo (Biudes et al., 2009). Existem várias metodologias para determinação dos coeficientes de digestibilidade aparente dos nutrientes e da energia dos alimentos. Para peixes destacam-se os métodos indiretos que com uso de indicadores.

Em peixes, esses estudos apareceram em maior volume a partir da década de 1960 (Sallun et al., 2002). Apesar do vasto conhecimento em nutrição de espécies exóticas, no Brasil, são poucos os trabalhos com espécies nativas. Consequentemente, não existem tabelas para formulação de rações para peixes como são encontradas para outros animais de produção, como aves e suínos (Sallun et al., 2002).

Poucas espécies de peixes nativos têm sido alvo de estudos dessa natureza. Abimorad et al. (2007), Oliveira et al. (2007) e Vidal Jr. et al. (2004) determinaram coeficiente de digestibilidade aparente de alimentos para tambaqui (Colossoma macropomum); Gonçalves \& Furuya (2004) para o piavuçu (Leporinus macrocephalus) e Sallum et al. (2002) para o matrinchã (Brycon cephalus). Com peixes de couro, destacam-se os trabalhos de Oliveira Filho \& Fracalossi (2006) com juvenis de jundiá (Rhamdia quelen) e de Gonçalves \& Carneiro (2003) com surubim (Pseudoplatystoma coruscans).

O objetivo neste trabalho foi determinar o valor nutritivo de alimentos energéticos para surubins juvenis por meio da caracterização bromatológica e da determinação do coeficiente de digestibilidade da matéria seca (MS), proteína bruta (PB) e energia bruta (EB).

\section{Material e Métodos}

Este trabalho foi realizado no Laboratório de Aquacultura da Escola de Veterinária da UFMG (LAQUA) em Belo Horizonte, Minas Gerais.

Realizou-se um ensaio para determinação dos coeficientes de digestibilidade aparente da matéria seca, proteína bruta e energia bruta de quatro ingredientes energéticos: fubá de milho, sorgo baixo tanino, farelo de arroz integral e quirera de arroz.

Foram utilizados 240 alevinos, com 30 g de peso médio distribuídos em tanques-rede cilíndricos de malha plástica de $80 \mathrm{~mm}$ (40 litros) dentro de tanques de fibra de vidro com 100 litros úteis apropriados para colheita de fezes, semelhantes ao modelo Guelf modificado por Cho \& Slinger (1979) e descrito por Sakomura \& Rostagno (2007), onde passaram por um novo período de adaptação de 15 dias às condições e dietas experimentais.

Foi usada água de poço artesiano apenas para reposição do volume do sistema de recirculação utilizado
(Ribeiro et al., 2003). A circulação de água nos tanques proporcionou troca de 50 litros de água por hora. A temperatura, a concentração de oxigênio dissolvido e o pH foram medidos diariamente pela manhã. O nível de nitrito foi monitorado semanalmente utilizando-se quites colorimétricos.

O delineamento experimental foi inteiramente casualizado com quatro dietas e quatro repetições. A unidade experimental foi composta de um tanque com 12 peixes.

A dieta-referência (Tabela 1 ) e as dietas experimentais foram confeccionadas no LAQUA, utilizando-se um misturador manual com capacidade de cinco quilos por batida e um moedor de carne para peletização das dietas. Após a etapa de mistura dos ingredientes, foi adicionada água a $60^{\circ} \mathrm{C}(50 \%)$ para facilitar a peletização. Para homogeneização do tamanho dos péletes, a ração úmida foi colocada em pequenas porções dentro de um saco plástico insuflado com ar e agitado até a obtenção de partículas de tamanho adequado $(6 \times 3 \mathrm{~mm}$, aproximadamente). Após essa etapa, as dietas foram secas em estufa de ventilação forçada a $55^{\circ} \mathrm{C}$ e armazenadas em freezer a $-18^{\circ} \mathrm{C}$ até o início do experimento.

A alimentação foi à vontade e o consumo de matéria seca foi de cerca de 2,5\% da biomassa estocada. Os horários de fornecimento das dietas foram às 0 h e 4h30, em virtude da maior aceitabilidade do alimento pelos peixes. A colheita de fezes foi realizada utilizando-se o sistema de Guelph modificado por Cho \& Slinger (1979) e descrito por Sakomura \& Rostagno (2007).

Antes do início das coletas de fezes, os animais foram adaptados às dietas experimentais por 15 dias. Nesse período, somente 10 horas após a primeira alimentação, foi possível colher quantidades significativas de fezes. Por essa razão, no período de coleta, às 8 h da manhã, os

Tabela 1 - Composição percentual da dieta-referência

\begin{tabular}{lr}
\hline Ingrediente & $(\%)$ \\
\hline Concentrado protéico de soja & 15,00 \\
Farinha de peixe & 30,16 \\
Plasma & 10,00 \\
Óleo de soja & 9,18 \\
Farelo de trigo & 6,00 \\
Milho & 10,60 \\
Farelo de soja & 6,70 \\
Glúten de milho 60 & 10,00 \\
Dl-metionina & 0,06 \\
Premix vitamínico-mineral* & 2,00 \\
Óxido de cromo & 0,10 \\
Bentonita & 0,20 \\
\hline
\end{tabular}

* Composição por quilo de produto: Vit. A $=1.200 .000$ UI; vit. D3 $=200.000$ UI vit. $\mathrm{E}=12.000 \mathrm{mg}$; vit. $\mathrm{K} 3=2400 \mathrm{mg}$; vit. $\mathrm{B} 1=4800 \mathrm{mg}$; vit. $\mathrm{B} 2=4800 \mathrm{mg}$; vit. B6 = $4000 \mathrm{mg}$; vit. B12 = $4800 \mathrm{mg}$; ác. fólico = $1200 \mathrm{mg}$; pantotenato de cálcio $=12.000 \mathrm{mg}$; vit. $\mathrm{C}=48.000 \mathrm{mg}$; biotina $=48 \mathrm{mg}$; colina $=65.000 \mathrm{mg}$; ácido nicotínico = $24.000 \mathrm{mg} ; \mathrm{Fe}=10.000 \mathrm{mg} ; \mathrm{Cu}=600 \mathrm{mg} ; \mathrm{Mn}=4000 \mathrm{mg}$; $\mathrm{Zn}=6000 \mathrm{mg} ; \mathrm{I}=20 \mathrm{mg} ; \mathrm{Co}=2 \mathrm{mg} ; \mathrm{Se}=20 \mathrm{mg}$. 
tanques eram limpos com uma esponja para retirada de partículas que pudessem contaminar as fezes e às $10 \mathrm{~h}$ era realizada uma drenagem brusca, de cerca de $10 \%$ do volume de cada tanque, para descarte das fezes acumuladas até o momento. Em seguida, eram colocados os coletores. A partir de então as fezes eram recolhidas a cada hora por meio da substituição do tubo coletor até as 17 h e o material de cada unidade experimental era armazenado em pool (da mesma unidade experimental). As colheitas se estenderam em média por sete dias até que se obtivesse quantidade de material suficiente para as análises laboratoriais.

Após o período experimental, todas as rações e amostras de fezes colhidas foram secas em estufa ventilada a $55^{\circ} \mathrm{C}$, moídas em peneira de $1 \mathrm{~mm}$, homogeneizadas e armazenadas em frascos plásticos para posterior análise no Laboratório de Nutrição da Escola de Veterinária da UFMG. Realizaram-se as análises de matéria seca (MS), cinzas, proteína bruta (PB), energia bruta (EB) e extrato etéreo (EE), segundo AOAC (2005). A determinação de cromo foi feita por espectrofotometria de absorção atômica (EAA), segundo Williams et al. (1962).

Para determinação dos coeficientes de digestibilidade aparente (CDA) da matéria seca, energia e proteína dos alimentos estudados, foi utilizada a metodologia de substituição de 30\% dos macronutrientes da dieta pelo alimento-teste numa ração-referência (Matterson, 1965). Para estimativa dos coeficientes de digestibilidade aparente, utilizou-se $0,1 \%$ de óxido crômico como indicador externo misturado à dieta.

Os coeficientes de digestibilidade aparente da matéria seca, energia e proteína das dietas-teste foram calculados de acordo com a fórmula descrita por Nose (1960): CDA da dieta $=100\left[1-\left(\% \mathrm{Cr}_{2} \mathrm{O}_{3}\right.\right.$ na dieta $/ \% \mathrm{Cr}_{2} \mathrm{O}_{3}$ nas fezes $) \times(\%$ nutriente ou energia nas fezes / \% nutriente ou energia na dieta)].

Já os coeficientes de digestibilidade aparente da matéria seca, energia e proteína dos alimentos avaliados foram calculados de acordo com a fórmula descrita por Cho \& Slinger (1979): CDA do alimento $=($ CDA da dieta-teste CDA da dieta-referência $) \times(\%$ dieta-referência / \% do ingrediente avaliado).

Os resultados obtidos foram submetidos à análise de variância (ANOVA) e comparados pelo teste de StudentNewman-Keuls (SNK) a 5\% de probabilidade pelo programa SAEG 8.0.

\section{Resultados e Discussão}

Os parâmetros de qualidade da água mantiveram-se dentro dos padrões recomendáveis para a produção de peixes de clima tropical (médias de oxigênio dissolvido de $5,1 \pm 0,6 \mathrm{mg}$ de $\mathrm{O}_{2} /$ litro no efluente, e temperatura de $\left.28 \pm 1^{\circ} \mathrm{C}\right)$. A temperatura média observada em todo o período experimental encontra-se dentro dos limites recomendados por Marques et al. (1992) para o surubim. Os valores de nitrito estiveram sempre abaixo de $0,30 \mathrm{mg} / \mathrm{litro}$ e o $\mathrm{pH}$ esteve sempre em 7,1 a 7,3.

As concentrações de proteína, energia e extrato etéreo da dieta-referência (Tabela 2) foram mais elevadas que o planejado na formulação, em função de diferenças entre os valores nutricionais tabelados e reais dos ingredientes utilizados. Contudo, a relação energia proteína real (103 kcal por mg de proteína) permaneceu próxima ao planejado (100 kcal por mg de proteína)

A composição dos alimentos avaliados (Tabela 3) é compatível com os valores descritos por Rostagno (2005).

Os resultados da comparação de médias comprovam que os coeficientes de digestibilidade aparente da matéria seca, proteína bruta e energia bruta variaram $(\mathrm{P}<0,05)$ entre os alimentos avaliados.

Os alimentos energéticos apresentaram coeficientes de digestibilidade aparente da matéria seca compatíveis para peixes carnívoros, devido aos níveis de amido nos ingredientes estudados. O milho e o farelo de arroz apresentaram os maiores coeficientes de digestibilidade aparente da matéria seca, seguidos pela quirera de arroz e pelo sorgo.

Os coeficientes de digestibilidade aparente da proteína bruta do fubá de milho, do farelo e da quirera de arroz não variaram significativamente entre si, oscilando entre 83,84 e $87,40 \%$. Os coeficientes de digestibilidade aparente da proteína bruta do farelo de arroz, da quirera e do sorgo, também foram semelhantes. Contudo, houve diferença significativa entre o fubá de milho e o sorgo para esse coeficiente de digestibilidade aparente. Já para a energia bruta, os coeficientes de digestibilidade aparente diferiram,

Tabela 2 - Composição nutricional da dieta-referência

\begin{tabular}{lcc}
\hline Composição nutricional & Calculada & Analisada $^{1}$ \\
\hline Proteína bruta & 46,00 & 48,50 \\
Energia bruta & $4.600,00$ & $4.994,00$ \\
Proteína digestível & 40,49 & 42,68 \\
Energia digestível & $3.484,00$ & $3.795,00$ \\
Extrato etéreo & 10,0 & 16,09 \\
Fibra bruta & 1,5 & 1,75 \\
Ca & 1,5 & 1,49 \\
P & 1,2 & 1,07 \\
P disponível & 0,87 & \\
Arginina & 2,88 & \\
Lisina & 2,92 & \\
Metionina & 1,00 & \\
\hline
\end{tabular}

${ }^{1}$ Laboratório de Nutrição Animal da Escola de Veterinária da UFMG. 
Tabela 3 - Composição nutricional dos ingredientes avaliados para juvenis de surubim ${ }^{1}$

\begin{tabular}{lcccc}
\hline Ingrediente & $\begin{array}{c}\text { Farelo de } \\
\text { arroz }\end{array}$ & Sorgo & $\begin{array}{c}\text { Quirera } \\
\text { de arroz }\end{array}$ & $\begin{array}{c}\text { Fubá de } \\
\text { milho }\end{array}$ \\
\hline Matéria seca (\%) & 87,94 & 87,56 & 90,34 & 87,19 \\
Proteína bruta (\%) & 13,86 & 9,23 & 7,97 & 6,34 \\
Energia bruta (kcal/kg) & 4.490 & 3.869 & 3.804 & 3.683 \\
Extrato etéreo (\%) & 16,37 & 2,34 & 2,91 & 1,5 \\
Cinzas (\%) & 8,64 & 1,72 & 0,89 & 1,35 \\
Cálcio (\%) & 0,1 & 0,02 & 0,03 & 0,04 \\
Fósforo (\%) & 1,56 & 0,21 & 0,14 & 0,21 \\
\hline
\end{tabular}

${ }^{1}$ Laboratório de Nutrição Animal da Escola de Veterinária da UFMG.

e foram maiores no farelo de arroz, seguido pelo milho, sorgo e pela quirera de arroz. O coeficiente de digestibilidade aparente da energia bruta foi mais alto para o farelo de arroz, possivelmente, em razão de sua composição, rica em gordura e pobre em amido. Considerando a maior concentração de amido em detrimento à de lipídeos da quirera de arroz e do sorgo, era previsível o resultado obtido para o surubim por se tratar de uma espécie carnívora.

O milho, apesar de possuir cerca de $62 \%$ de amido (Rostagno, 2005) e pouca gordura (1,5\%), apresentou digestibilidade da energia superior à do sorgo e da quirera de arroz e próxima à obtida para o farelo de arroz integral. Isso pode ser explicado pelo fato de o amido do milho ser mais digestível que o sorgo e a quirera de arroz, em virtude de sua composição. Segundo Teixeira et al. (1998), a origem e as características do amido são de grande importância na alteração das taxas de hidrólise in vivo e in vitro. Os principais componentes do amido são amilose e amilopectina: a amilose é mais solúvel e digerida mais rapidamente que a amilopectina (Lara, 2005). Nesse caso, o amido de milho possui maior concentração de amilose em relação à amilopectina se comparado ao amido do sorgo e da quirera de arroz. Neste contexto é fundamental considerar a forma de processamento da dieta, pois em dietas extrusadas a amilopectina é mais solúvel que em dietas peletizadas. Além disso, o milho possui baixo teor de amido resistente (2,5\%) (Teixeira et al., 1998).

Em comparação aos coeficientes de digestibilidade aparente da proteína bruta obtidos por Gonçalves \& Carneiro (2003) para alevinos de surubim (farelo de arroz 44,21\%, quirera $43,24 \%$, milho $64,18 \%$ e sorgo $44,87 \%$ ), a digestibilidade da proteína de todos os ingredientes energéticos neste trabalho foi muito superior (Tabela 4). Essas diferenças possivelmente estão relacionadas às fases de vida dos animais utilizados nestes trabalhos. No experimento realizado por Gonçalves \& Carneiro (2003) os animais pesavam cerca de 9,8 g enquanto os utilizados neste trabalho pesavam em torno de $30 \mathrm{~g}$. Já os resultados de digestibilidade da energia do trabalho dos autores citados (farelo de arroz 51,84\%, milho 64,95\%, sorgo 48,35\% e quirera 47,34\%) são mais próximos deste trabalho.

Khan (1994) encontrou, para o bagre tropical, (Mystus nemurus) elevado coeficiente de digestibilidade aparente da proteína bruta $(81,0 \%)$ e da energia bruta $(67,9 \%)$ do farelo de arroz. Wilson \& Poe (1985) obtiveram em bagre do canal coeficiente de digestibilidade aparente da proteína bruta da quirera de arroz de 73,0\%. Para o carnívoro marinho, "red drum" (Sciaenops oceallatus), McGoogan \& Reigh (1996) determinaram coeficientes de digestibilidade aparente da proteína bruta mais próximos aos encontrados neste experimento para surubim (milho 81,56\%, sorgo 77,08\% e farelo de arroz 77,15\%). Na espécie marinha carnívora, o híbrido "striped bass" (Morone saxatilis $\times$ M. chrysops), Sullivan \& Reigh (1995) obtiveram coeficientes de digestibilidade aparente da proteína bruta e energia bruta do milho de 86,7 e 40,67\%, respectivamente. Usmani et al. (2003), avaliando coeficientes de digestibilidade aparente da proteína bruta em bagres, encontraram valores de 77,3 a $85,0 \%$ para o milho, resultados mais próximos ao deste trabalho. O NRC (1993) traz coeficiente de digestibilidade aparente da proteína bruta do milho para truta de 95\%.

Em pesquisa com jundiá (Rhamdia quelen), Oliveira Filho \& Fracalossi (2006) encontraram coeficientes de digestibilidade aparente para matéria seca, proteína bruta e energia bruta do milho $(57,2,73,0$ e $59,1 \%)$ e da quirera de arroz (60,5, 80,7 e 64,8\%). Em tilápia-do-nilo nilótica (Oreochromis niloticus), Furuya et al. (2001) obtiveram coeficiente de digestibilidade aparente da proteína bruta do milho de $87,12 \%$.

Em diversos experimentos, mesmo em peixes carnívoros, a digestibilidade da fração proteica é elevada e compatível com as encontradaspara juvenis de surubim. Seixas Filho et al. (2001) concluíram que o arranjo intestinal do surubim é compatível com o da maioria dos peixes carnívoros, ou seja, quase retilíneo. Esses autores ressaltaram, no entanto, que o surubim apresenta algumas particularidades, como circunvoluções das alças finais do intestino médio, as quais podem ser vistas como possíveis adaptações para um regime onívoro, o que pode justificar a grande capacidade desse peixe em digerir ingredientes ricos em carboidratos amiláceos.

Os resultados de digestibilidade de alimentos energéticos encontrados para outros carnívoros e as características morfofisiológicas do trato digestivo desta espécie, discutidas por Seixas Filho et al. (2001), apontam 
Tabela 4 - Coeficientes de digestibilidade aparente da matéria seca, proteína bruta e energia bruta e proteína digestível e energia digestível dos alimentos energéticos

\begin{tabular}{|c|c|c|c|c|c|}
\hline Ingrediente & Fubá de milho & Farelo de arroz & Quirera de arroz & Sorgo & $\mathrm{CV}$ \\
\hline \multicolumn{6}{|l|}{ Coeficiente de digestibilidade } \\
\hline Matéria seca digestível (\%) & 54,31 & 52,48 & 36,49 & 33,27 & \\
\hline \multicolumn{6}{|l|}{ Coeficiente de digestibilidade } \\
\hline aparente da proteína bruta (\%) & $87,40 a$ & $83,84 \mathrm{ab}$ & $85,30 \mathrm{ab}$ & $81,11 b$ & 3,17 \\
\hline Proteína digestível (\%) & 5,54 & 11,62 & 6,80 & 7,49 & \\
\hline \multicolumn{6}{|l|}{ Coeficiente de digestibilidade } \\
\hline aparente da energia bruta (kcal/kg) & $62,43 b$ & $66,41 \mathrm{a}$ & $46,92 c$ & $47,76 \mathrm{c}$ & 3,45 \\
\hline Energia digestível (\%) & 2.299 & 2.982 & 1.785 & 1.848 & \\
\hline
\end{tabular}

Médias com letras minúsculas diferentes na mesma linha diferem $(\mathrm{P}<0,05)$.

que os dados obtidos para coeficientes de digestibilidade aparente dos alimentos avaliados não foram superestimados como pode parecer numa comparação direta com os dados de Gonçalves \& Carneiro (2003).

Além disso, deve-se considerar que, em peixes, a maior parte da fração nitrogenada é excretada pelas brânquias (Randall \& Wright, 1987), o que pode justificar a baixa concentração de nitrogênio nas fezes e conseqüente alta nos coeficientes de digestibilidade aparente. Essa informação sugere baixa eficácia do uso dos dados de proteína digestível na formulação de dietas para peixes, pois, considerando a importante excreção nitrogenada por via branquial, as diferenças entre os coeficientes de digestibilidade e metabolização da proteína são muito grandes. Portanto, é fundamental a padronização de métodos para estimar coeficientes de matabolização de proteína em peixes para obtenção de dados mais precisos para formulação de dietas para peixes.

\section{Conclusões}

Juvenis de surubim digerem com mais eficiência ingredientes energéticos ricos em gordura. Entre o fubá de milho, o farelo e a quirera de arroz e o sorgo, o farelo de arroz integral apresentou as maiores concentrações de proteína e energia digestíveis. Os coeficientes de digestibilidade aparente da proteína bruta e da energia bruta desses alimentos são compatíveis com sua utilização em dietas para esses animais e, no caso do sorgo e da quirera de arroz, são mais baixos.

\section{Agradecimentos}

À Secretaria Especial de Aqüicultura e Pesca da Presidência da República (SEAP-PR) pelo apoio estrutural; ao CNPq pela bolsa de doutorado e à Escola de Veterinária da UFMG.

\section{Referências}

ABIMORAD, E.G.; SQUASSONI, G.H.; CARNEIRO, D.J. Apparent digestibility of protein, energy and amino acids in some selected feed ingredients for pacu Piaractus mesopotamicus. Aquaculture nutrition, v.14, p.374-380, 2007.

BIUDES, J.F.V.; PEZZATO, L.E.; CAMARGO, A.F.M. Digestibilidade aparente da farinha de aguapé em tilápias-do-nilo. Revista Brasileira de Zootecnia, v.38, n.11, p.2079-2085, 2009.

BURKERT, D.; ANDRADE, D.R.; SIROL, R.N. et al. Rendimentos do processamento e composição química de filés de surubim cultivado em tanques-rede. Revista Brasileira de Zootecnia, v.37, n.7, p.1137-1143, 2008.

CHO, C.Y.; SLINGER, S.I. Apparent digestibility measurement in feedstuff for rainbow trout. In: WORLD SIMPOSIUM ON FINFISH NUTRITION AND FISHFEED TECHNOLOGY, Hamburg, 1978. Procedings... Heeneman: 1979. p.239-247.

FURUYA, W.M.; PEZZATO, L.E.; PEZZATO, A.C. et al. Coeficiente de digestibilidade e valores de aminoácidos digestíveis de alguns ingredientes para tilápia do Nilo (Oreochromis niloticus). Revista Brasileira de Zootecnia, v.30, n.4, p.1143-1149, 2001.

GONÇALVES, E.G.; CARNEIRO, D.J. Coeficiente de digestibilidade aparente da proteína e energia de alguns ingredientes utilizados em dietas para o pintado (Pseudoplatystoma coruscans). Revista Brasileira de Zootecnia, v.32, n.4, p.779-786, 2003.

GONÇALVES, G.S.; FURUYA, W.M. Digestibilidade aparente de alimentos pelo piavuçu, Leporinus macrocephalus. Acta Scientiarum, v.26, n.2, p.165-169, 2004.

KHAN, MS. Apparent digestibility coefficients for commom feed ingredients in formulated diets for tropical catfish, Mystus nemurus (Cuvier \& Valencienes). Aquaculture Fisheries Managements, v.25, p.167-174, 1994.

LARA, LB. Características físico-químicas do amido em alimentos comerciais para cães e gatos. In: SIMPÓSIO DE NUTRIÇÃO DE CÃES E GATOS, 2005, Lavras. Anais... Lavras: UFLA, 2005. 300p.

MARQUES, E.E.; AGOSTINHO, A.A.; SAMPAIO, A.A. et al. Alimentação, evacuação gástrica e cronologia da digestão de jovens de pintado Pseudoplatystoma coruscans (Siluriforme, Pimelodide) e suas relações com a temperatura ambiente. Revista Unimar, v.14, p.207-221, 1992.

MATTERSON, L.D; POTTER, LM; STUTZ, N. et al. The metabolizable energy of feed ingredients for chickens. Research Report n. 7 University of Connecticut, Agriculture Experimental Station, v.7, p.3-11, 1965.

McGOOGAN, B.B.; REIGH, R.C. Apparent digestibility of selected ingredients in red drum (Sciaenops ocellatus) diets. Aquaculture, v.141, p.233-244, 1996.

NATIONAL RESEARCH COUNCIL - NRC. Nutrient requirement of fish. Washington, D.C.: National Academic Press, 1993. 115p. 
NOSE, T. On the digestion of food protein by gold-fish (Carassius auratus L.) and rainbow trout (Salmo irideus G.). Bulletin Freshwater Fish, v.10, p.11-12, 1960

OLIVEIRA FILHO, P.R.C.; FRACALOSSI, D.M. Coeficientes de digestibilidade aparente de ingredientes para juvenis de jundiá. Revista Brasileira de Zootecnia, v.35, n.4, p.1581-1587, 2006.

OLIVEIRA, A.C.B.; MARTINELLI, L.A.; MOREIRA, M.Z. et al. Determination of apparent digestibility coefficient in fish by stable carbon isotopes. Aquaculture Nutrition, v.14, p.10-13, 2007.

RANDALL, D.J.; WRIGHT, P.A. Fish physiology and biochemistry. Amsterdam/Berkeley: Kugler Publications, 1987. v.3, n.3, p.107-120.

RIBEIRO, L.P.; SOUZA, S.N.; CREPALDI, D.V. et al. Evaluation of a recirculation systen in surubim $P$. coruscans culture. In: WORLD AQUACULTURE SOCIETY 2003, Salvador. Proceedings... World Aquaculture Society, 2003. p.632.

ROSTAGNO, H.S. Tabelas brasileiras para aves e suínos: composição de alimentos e exigências nutricionais. 2.ed. Viçosa, MG: UFV, Departamento de Zootecnia, 2005. 186p.

SAKOMURA, N.K.; ROSTAGNO, H.S. Métodos de pesquisa em nutrição de monogástricos. Jaboticabal: Funep, 2007. $283 p$.

SALLUM, W.B.; BERTECHINI, A.G.; LOGATO, P.V.R. et al. Coeficiente de digestibilidade aparente da matéria seca, proteína bruta e extrato etéreo de ingredientes de ração para o matrinchã (Brycon cephalus, gunther 1869). Ciência e Agrotecnologia, v.26, n.1, p.174-181, 2002.
SEIXAS FILHO, J.T.; BRÁS, J.M.; GOMIDE, A.T.M. et al. Anatomia funcional do intestino do Teleostei (Pisces) de agua doce surubim (Pseudoplatystoma coruscans - Agassiz, 1829). Revista Brasileira de Zootecnia, v.30, n.6, p.1670-1680, 2001.

SULLIVAN, J.A.; REIGH, R.C. Apparent digestibility of selected feedstuffs in diets for hybrid striped bass (Morene saxatilis $\times$ Morene chrysops). Aquaculture, v.138, p.313-322, 1995.

TEIXEIRA, E.A. Avaliação de alimentos e exigências de energia e proteína para juvenis de surubim (Pseudoplatystoma spp). 2008. 88f. Tese (Doutorado em Zootecnia) - Escola de Veterinária da UFMG, Belo Horizonte.

TEIXEIRA, M.A.V.; CIACCO, C.F.; TAVARES, D.Q. et al. Ocorrência e Caracterização do amido resistente em amidos de milho e de banana. Ciência e Tecnologia de Alimentos, v.18, n.2, 1998.

USMANI, N.; AHMAD, K.J.; KHAN, M.A. Nutrient digestibility studies in Heteropneustes fossilis, Clarias batrachus (Linnaeus) and C. gariepinus (Burchell). Aquaculture Research, v.34, p.1247-1253, 2003.

VIDAL JR., M.V.; DONZELE, J.L.; ANDRADE, D.R. et al. Determinação da digestibilidade da matéria seca e da proteína bruta do fubá de milho e do farelo de soja para tambaqui (Colossoma macropomum), utilizando-se técnicas com uso de indicadores internos e externos. Revista Brasileira de Zootecnia, v.33, n.6, p.2193-2200, 2004.

WILSON, R.P.; POE, W.E. Apparent digestible protein and energy coefficients of common feed ingredients for channel catfish. Progressive Fisheries Culturist, v.47, n.3, p.154-158, 1985. 